\title{
Avaliação de Equações de Predição de Exigências Energéticas na Alimentação de Frangas de Postura1
}

\author{
Nilva Kazue Sakomura², Mônica Reis Bittencourt Benatti ${ }^{3}$, Roberta Basaglia ${ }^{3}$, Rafael Neme ${ }^{3}$, \\ Flávio Alves Longo ${ }^{3}$
}

\begin{abstract}
RESUMO - O objetivo do presente estudo foi testar a validade de equações de predição de exigências energéticas para frangas de postura, as quais foram determinadas em estudos anteriores realizados na Faculdade de Ciências Agrárias e Veterinárias da UNESP Jaboticabal. O delineamento experimental utilizado foi o inteiramente casualizado com três tratamentos e seis repetições compostas por 18 aves no período de 3 a 8 semanas, 15 aves de 9 a 12 semanas e 12 aves de 13 a 18 semanas de idade. Os tratamentos consistiram em comparar três diferentes formas de se alimentar as aves: alimentação à vontade, alimentação de acordo com as recomendações para a linhagem e alimentação de acordo com as equações de predição das exigências de energia metabolizável (EM). Os tratamentos foram avaliados por intermédio do desempenho das aves durante o período de crescimento e na fase de produção. No período de 3 a 8 semanas de idade, as aves alimentadas de acordo com as equações de predição de EM apresentaram menor consumo de ração e de energia, o que determinou menor peso corporal e uniformidade insatisfatória. Em função dos resultados da fase de 3 a 8 semanas de idade, foi adotada uma correção na equação de predição das exigências de EM para as fases seguintes, acrescentando-se uma porcentagem de 37\% sobre as exigências de EM para mantença, valor relativo às atividades das aves. Às 18 semanas de idade, a ingestão de EM foi maior para o tratamento à vontade, sendo que as aves de todos os tratamentos apresentaram peso corporal superior ao proposto pelo manual e boa uniformidade. O experimento teve continuidade durante a fase de produção, sendo que os tratamentos aplicados na fase de crescimento não afetaram o desempenho produtivo das aves.
\end{abstract}

Palavras-chave: desempenho de frangas de postura, equação de predição, exigências energéticas

\section{Evaluation of Prediction Equations for Energy Requirements in Pullets Feeding}

ABSTRACT - The objective of this work was to evaluate the validity of prediction equation of metabolizable energy requirements, that was previously determined at Faculdade de Ciências Agrárias e Veterinárias of UNESP - Jaboticabal. The pullets were distributed in a randomized design with three treatments and six replication of 18 pullets from 3 to 8 wk-age, 15 birds from 9 to 12 wk-age and 12 birds from 13 to 18 wk-age. The treatments consisted of comparing the performance of pullets feeding according to: ad libitum feeding, the strain recommendation and prediction equations for metabolizable energy (ME) requirements. The effect of treatments was evaluated in the growing phase and during the production phase to verify the effect of programs feeding during the growing on the egg production. From 3 to 8 weeks, the ME prediction equations promoted less feed and ME intakes than other treatments, and consequently these pullets showed lower body weight and smaller uniformity. In the following phases, an addition of 37\% to ME maintenance requirement was used in order to correct the ME requirement of prediction equation. At 18 weeks, the ad libitum feeding showed the highest ME intake and birds of all treatments showed higher body weight than the strain recommendations. During the production phase, the treatments did not affect the productive performance.

Key Words: energy requirements, prediction equation, pullets performance

\section{Introdução}

A principal razão para o aumento da produtividade das poedeiras parece estar associada a melhores condições oferecidas para o crescimento das frangas, tendo como conseqüência frangas mais precoces e com melhores condições físicas que anos atrás
(Moretti, 1992; Summers, 1992). A melhoria no potencial genético das aves refletiu em aumento na produção de ovos e diminuição na idade de maturidade sexual, o que muitas vezes pode ser um problema, pois as aves dispõem de menos tempo para atingir o desenvolvimento corporal ideal. Esse fator é de extrema importância, uma vez que o peso do ovo está

\footnotetext{
${ }^{1}$ Parte da dissertação da segunda autora e parte do Projeto Temático financiado pela FAPESP.

${ }^{2}$ Professora do Departamento de Zootecnia da FCAV - UNESP - Jaboticabal, SP. E.mail:sakomura@fcav.unesp.br (autor para correspondência).

${ }^{3}$ Pós-graduados em Zootecnia pela FCAV - UNESP - Jaboticabal, SP
} 
diretamente relacionado ao peso corporal à maturidade sexual e aves que possuem ovos pequenos em início de produção produzirão sempre ovos menores (Leeson \& Summers, 1997).

Para atingir a maturidade sexual, é importante que o fornecimento de nutrientes seja adequado, dando condições para bom desenvolvimento corporal, empenamento e formação do aparelho reprodutor, evitando redução no crescimento da ave. Assim, o consumo de energia deve ser estimulado para que a ave não apresente menor peso corporal e, conseqüentemente, menos reservas energéticas, as quais serão imprescindíveis nos momentos mais críticos da produção (Moretti, 1992). Por outro lado, Chandramouli (1988) observou que as aves de postura tendem a consumir mais energia quando alimentadas à vontade, aumentando o ganho de peso principalmente como gordura depositada, refletindo em maior exigência de energia para mantença e, conseqüentemente, perdendo em eficiência produtiva. De acordo com Chwalibog (1992), poedeiras alimentadas à vontade apresentam o consumo energético $10 \%$ superior ao necessário.

Em função da falta de estudos direcionados à fase de crescimento de aves de postura, o manejo nutricional nesta fase fica condicionado aos níveis de nutrientes preconizados pelos manuais de criação e, no que se refere às exigências de energia, é restrito às condições em que é avaliado.

Silva et al. (1997), em estudos realizados na Faculdade de Ciências Agrárias e Veterinárias de Jaboticabal - UNESP, determinaram equações de predição das exigências diárias de energia metabolizável para aves de postura na fase de crescimento, tendo como base o método fatorial. Contudo, antes de indicar o uso destas equações a nível prático, é importante testar sua validade. De acordo com Sakomura (1996), estas equações de predição poderão ser utilizadas se forem constatados bons resultados, caso contrário, deverão ser feitos ajustes para que a equação reflita a necessidade real da ave.

O presente trabalho foi conduzido com o objetivo de testar a validade de equações de predição desenvolvidas na UNESP - Jaboticabal, para estimar as exigências de EM para frangas de postura na fase de crescimento e avaliar o efeito da alimentação utilizando essas equações no desempenho produtivo das aves.

\section{Material e Métodos}

O experimento envolveu duas etapas, o período de crescimento e o de postura, sendo que em ambos as aves foram criadas no sistema de gaiolas.

Fase de crescimento

O período de crescimento compreendeu três fases: Fase I ( 3 a 8 semanas de idade), Fase II (9 a 12 semanas de idade) e Fase III (13 a 18 semanas de idade). Inicialmente, foram utilizadas 600 frangas de postura da linhagem Lohmann LSL com duas semanas de idade, distribuídas inteiramente ao acaso em três tratamentos e seis repetições, sendo que o número inicial de aves para cada parcela para a Fase I foi 18, e para as Fases II e III, 15 e 12 aves, respectivamente. O número de aves por parcela diferiu entre as fases, em função de descartes ao final de cada uma, com o objetivo de buscar melhor uniformidade de peso em cada tratamento.

Os tratamentos utilizados consistiram em diferentes fornecimentos de ração para as aves: fornecimento de ração à vontade; fornecimento de ração controlado, conforme recomendação do manual para a linhagem; e fornecimento de ração para atender as exigências diárias de EM determinadas pelas equações de predição.

As equações de predição de EM testadas em cada fase foram: 3 a 8 semanas - $\mathrm{EM}=86,12 \cdot \mathrm{P}^{0,75}+$ $4,11 . \mathrm{G}+2 \mathrm{P}(21-\mathrm{T}) ; 9$ a 12 semanas $-\mathrm{EM}=$ $135,56 * . P^{0,75}+5,78 . G+2 P(21-T)$; e 13 a 18 semanas - $\mathrm{EM}=159,25^{*} \cdot \mathrm{P}^{0,75}+7,32 . \mathrm{G}+2 \mathrm{P}(21-\mathrm{T})$, em que: $\mathrm{EM}=$ exigência de energia metabolizável em kcal/ ave/dia, PV = peso vivo corporal (g), G = ganho de peso (g) e $\mathrm{T}$ = temperatura média da semana anterior $\left({ }^{\circ} \mathrm{C}\right)$. *Valores já acrescidos de $37 \%$ de energia metabolizável para mantença relativo às atividades das aves.

Em função de que ao final de 8 semanas de idade as aves que receberam alimentação de acordo com a equação de predição de exigências de EM apresentaram peso corporal muito inferior às demais, o que foi atribuído à falta de energia para as atividades normais da ave, foi feita correção de 37\% no valor da energia estimada para mantença para suprir essas deficiências, segundo a recomendação de Scott et al. (1982).

Nas equações de predição de exigência de EM, determinadas em estudos anteriores por Silva et al. (1997), foi introduzido um fator para correção da 
temperatura ambiente, de acordo com Sakomura et al. (1995).

As rações experimentais foram formuladas à base de milho e farelo de soja, e os tratamentos à vontade e controlado receberam rações formuladas de acordo com os níveis estabelecidos pelo manual da linhagem (Tabela 1). Para o tratamento relacionado às equações de predição de EM, as exigências foram determinadas com base no peso corporal metabólico $\left(\mathrm{PV}^{0,75}\right)$ obtido para cada tratamento no início da semana, no ganho de peso (G) estimado para a semana, segundo o manual, e na temperatura média (T) da semana anterior.

As rações fornecidas para as aves do tratamento da equação foram formuladas semanalmente de forma que a ingestão diária dos nutrientes, com exceção da EM, fosse semelhante entre os tratamentos. Em função das diferenças no consumo, foram determinados os níveis dos demais nutrientes (Tabela 2).

A temperatura média da semana foi calculada de acordo com a fórmula indicada: $\mathrm{T}=\left(\mathrm{T}_{\text {máx }}+\mathrm{T}_{\text {min }}\right.$ $\left.+\mathrm{T}_{9}+2 \mathrm{~T}_{21}\right) / 5$, em que $\mathrm{T}_{\text {máx }}$ - temperatura máxima do dia, $\mathrm{T}_{\min }$ - temperatura mínima do dia e $\mathrm{T}_{9}$ - tempera-

Tabela 1 - Níveis nutricionais das rações formuladas para os períodos de 3 a 8 semanas (fase I) e 9 a 18 semanas de idade (fases II e III)

Table 1 - Nutritional diets level from 3 to 8 (phase I) and from 9 to 18 (phase II and III) weeks of age

\begin{tabular}{|c|c|c|}
\hline \multirow{2}{*}{$\begin{array}{l}\text { Nutrientes } \\
\text { Nutrients }\end{array}$} & \multicolumn{2}{|c|}{$\begin{array}{l}\text { Semanas de idade } \\
\text { Weeks of age }\end{array}$} \\
\hline & 3 a 8 & 9 а 18 \\
\hline $\begin{array}{l}\text { Energia metabolizável (kcal/kg) } \\
\text { Metabolizable energy }\end{array}$ & 2850 & 2850 \\
\hline Proteína bruta (\%) & 18,00 & 16,50 \\
\hline $\begin{array}{l}\text { Crude protein } \\
\text { Cálcio (\%) } \\
\text { Calcium }\end{array}$ & 1,10 & 0,90 \\
\hline $\begin{array}{l}\text { Fósforo disponível (\%) } \\
\text { Available phosphorus }\end{array}$ & 0,40 & 0,30 \\
\hline $\begin{array}{l}\text { Metionina (\%) } \\
\text { Methionine }\end{array}$ & 0,35 & 0,30 \\
\hline $\begin{array}{l}\text { Met. + Cist. (\%) } \\
\text { Met+Cys }\end{array}$ & 0,66 & 0,59 \\
\hline $\begin{array}{l}\text { Lisina (\%) } \\
\text { Lysine }\end{array}$ & 0,91 & 0,80 \\
\hline $\begin{array}{l}\text { Treonina (\%) } \\
\text { Threonine }\end{array}$ & 0,70 & 0,64 \\
\hline $\begin{array}{l}\text { Triptofano (\%) } \\
\text { Tryptophan }\end{array}$ & 0,24 & 0,22 \\
\hline
\end{tabular}

tura às $9 \mathrm{~h}$; $\mathrm{T}_{21}$ - temperatura às $21 \mathrm{~h}$. A temperatura mínima no período variou de 12,7 a $21,4^{\circ} \mathrm{C}$, a máxima de 25,1 a $32,9^{\circ} \mathrm{C}$ e a média de 17,8 a $24,7^{\circ} \mathrm{C}$.

Na fase de crescimento, foram analisados o peso e o ganho de peso corporal, o consumo de ração e a uniformidade do lote, a qual foi calculada ao início e ao final de cada fase, retirando-se as aves que se apresentavam $10 \%$ acima ou abaixo do peso médio do tratamento. Ao final da fase de crescimento (18 semanas), foram abatidas duas aves por parcela para análise de composição corporal. As aves destinadas ao abate foram submetidas a um jejum de 24 horas e, após o abate, feito por deslocamento da coluna cervical, foram levadas ao freezer para congelamento. Depois de congeladas, as carcaças foram cortadas em pedaços com serra elétrica e processadas em moinho de carne por três vezes consecutivas para obtenção de um material homogêneo. Uma amostra foi seca em estufa com circulação de ar $\left( \pm 55^{\circ} \mathrm{C}\right)$, por 72 horas, para obtenção de amostra seca ao ar (ASA). As amostras secas foram moídas novamente e enviadas ao laboratório para análise de matéria seca, extrato etéreo e proteína bruta, de acordo com AOAC (1997). Fase de produção

Às 20 semanas de idade, foi realizada pesagem e uniformização das aves de cada parcela, permanecendo oito aves por unidade experimental. Esta etapa do experimento teve duração de quatro ciclos de 28 dias, compreendendo o período de 20 a 35 semanas de idade, com o objetivo de avaliar se os tratamentos aplicados na fase de crescimento tiveram efeito no desempenho produtivo das aves.

A ração experimental foi a mesma para todos os tratamentos, sendo fornecida à vontade duas vezes ao dia. Os níveis nutricionais da ração foram: $2850 \mathrm{kcal} / \mathrm{kg}$ de EM, 18\% de proteína bruta, 3,5\% de cálcio e $0,45 \%$ de fósforo disponível, seguindo as recomendações do manual de criação da linhagem.

Na fase de produção, quantificaram-se o peso corporal ao início e ao final do experimento, consumo de ração, produção de ovos, massa de ovos (g/dia) e conversão alimentar (kg de ração/dúzia de ovo). A pesagem dos ovos foi feita ao final de cada ciclo de produção, durante três dias consecutivos.

A análise de variância dos dados foi realizada com o auxílio do programa computacional ESTAT (Sistema de Análises Estatísticas e Genéticas, UNESP-Jaboticabal, 1994) e as médias, comparadas pelo teste Tukey, a 5\% de probabilidade. 


\section{Resultados e Discussão}

Fase de crescimento

Na Tabela 3, são apresentadas as médias para consumo de ração e ingestão de EM e de proteína bruta nos períodos de crescimento. As aves alimentadas à vontade apresentaram maior consumo de ração durante a fase de crescimento, implicando em maior ingestão de EM, exceto entre 13 e 18 semanas de idade, em que o consumo de ração e de energia foi semelhante ao das aves alimentadas de acordo com a equação de EM. O consumo de ração e de EM fornecidos pela equação entre 3 a 8 semanas de idade foram inferiores às exigências das aves, sendo que, após o acréscimo de $37 \%$ nas exigências para mantença, de acordo com a recomendação de Scott et al. (1982), o consumo de ração e de EM proporcionado pelo tratamento da equação se comportou de maneira semelhante ao tratamento controlado, com exceção da fase compreendida entre 13 e 18 semanas de idade.

A deficiência energética proporcionada pela equação foi atribuída ao fator mantença, relativo às atividades, indicando a necessidade de melhor ajuste para que a equação se adeque às necessidades das aves. Segundo Scott et al. (1982), os requerimentos energéticos das aves jovens podem ser divididos em mantença e crescimento, sendo que a energia fornecida para mantença deve atender ao metabolismo basal relacionado à manutenção das atividades metabólicas vitais e às atividades das aves.

O peso corporal foi reflexo da ingestão de energia, sendo que entre 3 e 8 semanas as aves alimentadas à vontade atingiram maior peso e ganho de peso em relação aos demais tratamentos (Tabela 4). Nesse período, o tratamento da equação de predição de EM promoveu menor ingestão de alimento e de energia em relação aos demais tratamentos, resultando, portanto, em menor ganho de peso e peso corporal.

Recentemente, um novo manual de criação da linhagem foi elaborado, onde algumas metas de peso, assim como alguns níveis nutricionais da ração, foram alteradas. É interessante ressaltar que as aves, embora tenham sido alimentadas de acordo com o manual antigo, muitas vezes atingiram o peso corporal recomendado pelo manual da Lohmann (2000), o que não ocorreu na fase entre 3 e 8 semanas de idade, exceto para o tratamento à vontade. As recomendações do manual de criação (2000) variam entre 600 e 640 g de peso corporal às 8 semanas de idade.

Às 12 semanas de idade, o peso corporal do tratamento da equação e do tratamento controlado foi próximo ao recomendado para a linhagem segundo os manuais Lohmann (1995, 2000), de 940-960 g e 920 $980 \mathrm{~g}$, respectivamente. As aves do tratamento à

Tabela 2 - Níveis nutricionais das rações formuladas semanalmente, para o tratamento da equação de predição das exigências de energia metabolizável

Table 2 - Nutritional levels of diets formulated weekly for the prediction equations of metabolizable energy requirements

\begin{tabular}{cccccc}
\hline $\begin{array}{c}\text { Idade (sem) } \\
\text { Age (weeks) }\end{array}$ & $\begin{array}{c}\text { Proteína } \\
\text { Protein } \\
(\%)\end{array}$ & $\begin{array}{c}\mathrm{EM} \\
\text { ME } \\
(\mathrm{kcal} / \mathrm{kg})\end{array}$ & $\begin{array}{c}\mathrm{Ca} \\
(\%)\end{array}$ & $\begin{array}{c}\text { P disp. } \\
\text { Available P } \\
(\%)\end{array}$ & $\begin{array}{c}\text { Met + Cis } \\
\text { Met + Cys } \\
(\%)\end{array}$ \\
\hline 3 & 20,7 & 2850 & 1,3 & 0,5 & 0,7 \\
4 & 22,6 & 2850 & 1,4 & 0,5 & 0,8 \\
5 & 25,0 & 2850 & 1,5 & 0,6 & 0,9 \\
6 & 22,0 & 2850 & 1,3 & 0,5 & 0,8 \\
7 & 26,7 & 2850 & 1,3 & 0,4 & 0,8 \\
8 & 25,5 & 2850 & 1,6 & 0,6 & 0,9 \\
9 & 19,0 & 2850 & 1,0 & 0,3 & 0,7 \\
10 & 18,9 & 2850 & 1,0 & 0,3 & 0,7 \\
11 & 14,0 & 2850 & 0,8 & 0,3 & 0,6 \\
12 & 15,1 & 2850 & 0,8 & 0,3 & 0,6 \\
13 & 15,3 & 2850 & 0,8 & 0,3 & 0,6 \\
14 & 15,6 & 2850 & 0,9 & 0,3 & 0,6 \\
15 & 14,8 & 2850 & 0,8 & 0,3 & 0,6 \\
16 & 15,3 & 2850 & 0,8 & 0,3 & 0,6 \\
17 & 15,4 & 2850 & 0,8 & 0,3 & 0,6 \\
18 & 13,8 & 2850 & 0,8 & 0,3 & 0,5 \\
\hline
\end{tabular}

R. Bras. Zootec., v.33, n.3, p.575-584, 2004 
vontade atingiram peso corporal pouco acima $(1000,8)$ do recomendado pelo manual de criação Lohmann (2000). Segundo Scott et al. (1982), o alto peso corporal pode comprometer o desempenho produtivo das aves, pois a gordura pode envolver órgãos vitais e prejudicar a produção.

Às 18 semanas de idade, as aves alimentadas de acordo com a equação de predição apresentaram peso corporal superior aos demais tratamentos, indicando recuperação (Tabela 4). Nessa idade, todos os tratamentos apresentaram peso corporal superior ao preconizado pelo manual de criação da linhagem Lohmann (1995), (1250 a 1270 g), inclusive o tratamento de alimentação controlada, que deveria fornecer uma ração com níveis nutricionais e quantidades de ração ideais para a linhagem. Por outro lado, este tratamento proporcionou peso corporal mais próximo ao recomendado pelo manual Lohmann (2000), de 1280 a $1360 \mathrm{~g}$.

Embora as aves alimentadas à vontade tenham apresentado maior consumo de ração, energia e proteína em relação os demais tratamentos (Tabela 3), foram as aves do tratamento da equação de EM que apresentaram maior ganho de peso no período de crescimento (Tabela 4). Este fato pode ter ocorrido em decorrência de crescimento compensatório a partir da segunda fase, quando foi aumentado o fornecimento de energia, mediante adição do fator para correção na energia de mantença para as atividades das aves.

Leeson \& Summers (1997) recomendam peso corporal igual ou ligeiramente acima do recomendado

Tabela 3 - Médias para consumo de ração (g) e ingestão de energia metabolizável (kcal) e de proteína bruta (g) por ave nos períodos de 3 a 8, 9 a 12, 13 a 18 e 3 a 18 semanas de idade

Table 3 - Means of feed intake $(\mathrm{g})$ and metabolizable energy ( $\mathrm{kcal}$ ) and crude protein $(\mathrm{g})$ intake from 3 to 8,9 to 12,13 to 18 and 3 to18 weeks of age

\begin{tabular}{|c|c|c|c|c|}
\hline \multirow[t]{2}{*}{$\begin{array}{l}\text { Tratamento } \\
\text { Treatment }\end{array}$} & \multicolumn{4}{|c|}{$\begin{array}{l}\text { Consumo de ração (g) } \\
\text { Feed intake }(g)\end{array}$} \\
\hline & $\begin{array}{c}3 \text { a } 8 \text { semanas } \\
3 \text { to } 8 \text { weeks }\end{array}$ & $\begin{array}{c}9 \text { a } 12 \text { semanas } \\
9 \text { to } 12 \text { weeks }\end{array}$ & $\begin{array}{c}13 \text { a } 18 \text { semanas } \\
13 \text { to } 18 \text { weeks }\end{array}$ & $\begin{array}{c}3 \text { a } 18 \text { semanas } \\
3 \text { to } 18 \text { weeks }\end{array}$ \\
\hline $\begin{array}{l}\text { À vontade } \\
\text { Ad libitum }\end{array}$ & $1528,7 \mathrm{a}$ & $1855,3 \mathrm{a}$ & $3063,2 \mathrm{a}$ & $6449,5 \mathrm{a}$ \\
\hline $\begin{array}{l}\text { Controlado } \\
\text { Controled }\end{array}$ & $1451,7 \mathrm{~b}$ & $1661,8 b$ & $2807,8 b$ & $5921,3 b$ \\
\hline $\begin{array}{l}\text { Equação EM } \\
\text { ME equation }\end{array}$ & $1119,3 \mathrm{c}$ & $1683,4 b$ & $3071,4 \mathrm{a}$ & $5877,8 b$ \\
\hline \multirow[t]{2}{*}{$\overline{\mathrm{CV}(\%)}$} & 2,19 & 1,06 & 1,46 & 0,85 \\
\hline & \multicolumn{4}{|c|}{$\begin{array}{c}\text { Ingestão de energia metabolizável (kcal) } \\
\text { Metabolizable energy intake ( } \mathrm{kcal})\end{array}$} \\
\hline $\begin{array}{l}\text { À vontade } \\
\text { Ad libitum }\end{array}$ & $4375,1 \mathrm{a}$ & $5287,9 a$ & $8730,3 a$ & 18.393a \\
\hline $\begin{array}{l}\text { Controlado } \\
\text { Controled }\end{array}$ & 4113,6b & 4736,1b & $8002,1 \mathrm{~b}$ & $16.852 b$ \\
\hline $\begin{array}{l}\text { Equação EM } \\
\text { ME equation }\end{array}$ & $3190,0 \mathrm{c}$ & $4797,8 \mathrm{~b}$ & $8761,8 a$ & $16.750 \mathrm{~b}$ \\
\hline \multirow[t]{2}{*}{ CV (\%) } & 2,07 & 1,06 & 1,45 & 0,84 \\
\hline & \multicolumn{4}{|c|}{$\begin{array}{c}\text { Ingestão de proteína (g) } \\
\text { Protein intake }(\mathrm{g})\end{array}$} \\
\hline $\begin{array}{l}\text { À vontade } \\
\text { Ad libitum }\end{array}$ & 275,17 a & $306,1 \mathrm{a}$ & $497,1 \mathrm{a}$ & $1078,4 \mathrm{a}$ \\
\hline $\begin{array}{l}\text { Controlado } \\
\text { Controled }\end{array}$ & $259,82 b$ & 274,2 b & 463,3b & $997,4 b$ \\
\hline $\begin{array}{l}\text { Equação EM } \\
\text { ME equation }\end{array}$ & 268,87 a & $275,0 \mathrm{~b}$ & $462,8 b$ & $1006,7 b$ \\
\hline$\overline{C V(\%)}$ & 1,81 & 1,06 & 3,75 & 1,69 \\
\hline
\end{tabular}

Médias, na mesma coluna, seguidas de diferentes letras diferem $(P<0,05)$ entre si pelo teste Tukey. Mean, in the same column, followed by different letters are different $(P<.05)$ by Tukey test. 
para aves de postura para obtenção de melhor desempenho, o que difere da opinião de Scott et al. (1982). Uma explicação para estas diferenças pode ser atribuída ao fato de a genética das aves de postura, atualmente, ser muito diferente e, segundo Leeson \& Summers (1989), tem efeito na resposta da franga.

O consumo de proteína bruta do tratamento à vontade entre 3 e 8 semanas de idade foi igual ao tratamento da equação de EM (Tabela 3), sendo superior ao controlado, que deveria apresentar consumo de proteína igual ao tratamento da equação. Isso não ocorreu devido ao baixo consumo de ração das aves do tratamento controlado em relação ao proposto pelo manual de criação da linhagem Lohmann (1995, 2000), que neste período deveria ser de $1512 \mathrm{~g}$. As aves que receberam tratamento à vontade atingiram o peso corporal recomendado pelo manual da linhagem (590-610 g), enquanto as demais apresentaram peso inferior. Esses resultados indicam que os consumos de energia e proteína afetaram o ganho de peso e o peso corporal das aves em crescimento, o que também foi observado por Summers et al. (1987) e Lesson \& Summers (1982).

Observou-se ainda que a aplicação da correção para as atividades da ave nas exigências de mantença na equação de EM, de acordo com Scott et al. (1982), promoveu peso corporal superior ao recomendado pelo manual, provavelmente devido ao maior consumo de energia. O excesso de energia pode ter causado obesidade que pode ser prejudicial ao desempenho produtivo das aves. Assim, seria interessante a realização de mais estudos para determinação mais precisa das exigências de frangas em crescimento ou a determinação de um fator de correção que permita melhor ajuste na equação, levando em consideração a energia gasta nas atividades das aves.

O fato de as aves terem apresentado peso corporal e ganho de peso superiores ao recomendado pelo manual de criação da linhagem pode ter efeitos benéficos na produção de ovos, pois, segundo Leeson \& Summers (1997), as aves que possuem reservas energéticas próximo ao pico de produção são menos susceptíveis a problemas de falta de energia para suportar seu estado fisiológico. Além disso, há um conceito de que as frangas mais precoces atingem um limiar de massa corporal e iniciam a produção, quando alcançam idade fisiológica mínima, enquanto as aves mais tardias não possuem a massa corporal requerida para a produção nessa mesma idade. Assim, as aves que apresentarem peso corporal ideal ou pouco acima do recomendado poderão ser mais precoces e mais produtivas.

Na Tabela 5, são apresentados os dados de uniformidade no início e final do período de crescimento. De acordo com os dados apresentados, a equação de predição de EM promoveu pior uniformidade das aves entre 3 e 8 semanas de idade, pois as aves mais vorazes consumiram mais alimento e tiveram melhor desenvolvimento corporal; as demais não consumiram a quantidade necessária de nutrientes, já que a quantidade de alimento foi limitada. Nessa fase, somente as aves alimentadas à vontade apresentaram uniformidade satisfatória, pouco superior ao recomendado pelo manual de criação da linhagem (80\%).

Tabela 4 - Médias de peso corporal $(\mathrm{g})$ às 8, 12 e 18 semanas de idade e ganho de peso $(\mathrm{g})$ entre 3 a 8,9 a 12,13 a 18 e 1 a 18 semanas de idade

Table 4 - Mean of live weight (g) at 8, 12 and 18 weeks of age and weight gain from 3 to 8, 9 to 12,13 to 18 and 3 to 18 weeks

\begin{tabular}{|c|c|c|c|c|c|c|c|}
\hline \multirow[t]{2}{*}{$\begin{array}{l}\text { Tratamento } \\
\text { Treatment }\end{array}$} & \multicolumn{3}{|c|}{$\begin{array}{l}\text { Peso corporal (g) } \\
\text { Live weight }(\mathrm{g})\end{array}$} & \multicolumn{4}{|c|}{$\begin{array}{c}\text { Ganho de peso (g) } \\
\text { Weight gain }(\mathrm{g})\end{array}$} \\
\hline & $\begin{array}{c}8 \mathrm{sem} \\
8 w k\end{array}$ & $\begin{array}{l}12 \mathrm{sem} \\
12 \mathrm{wk}\end{array}$ & $\begin{array}{c}18 \mathrm{sem} \\
18 \mathrm{wk}\end{array}$ & $\begin{array}{c}3 \text { a } 8 \text { sem } \\
3 \text { to } 8 w k\end{array}$ & $\begin{array}{l}9 \text { a } 12 \mathrm{sem} \\
9 \text { to } 12 \mathrm{wk}\end{array}$ & $\begin{array}{c}13 \text { a } 18 \text { sem } \\
13 \text { to } 18 \mathrm{wk}\end{array}$ & $\begin{array}{l}3 \text { a } 18 \text { sem } \\
3 \text { to } 18 \text { wk }\end{array}$ \\
\hline $\begin{array}{l}\text { À vontade } \\
\text { Ad libitum }\end{array}$ & $605,6 \mathrm{a}$ & $1000,8 \mathrm{a}$ & $1415,9 b$ & $540,93 a$ & $395,18 b$ & $415,07 b$ & $1351,2 b$ \\
\hline $\begin{array}{l}\text { Controlado } \\
\text { Controled }\end{array}$ & 549,2 b & $951,7 \mathrm{~b}$ & $1382,6 \mathrm{c}$ & $484,83 b$ & $402,43 b$ & $430,63 b$ & $1317,9 \mathrm{c}$ \\
\hline $\begin{array}{l}\text { Equação EM } \\
\text { ME equation }\end{array}$ & $477,4 \mathrm{c}$ & 954,7b & 1448,2 a & $383,05 c$ & 507,18 a & 493,53a & 1383,9 a \\
\hline CV (\%) & 1,90 & 1,30 & 1,05 & 2,16 & 2,14 & 3,65 & 1,09 \\
\hline
\end{tabular}

Médias, na mesma coluna, seguidas de diferentes letras diferem $(P<0,05)$ entre si pelo teste Tukey.

Mean, in the same column, followed by different letters are different $(P<.05)$ by Tukey test.

\section{R. Bras. Zootec., v.33, n.3, p.575-584, 2004}


A uniformidade ao início de 9 e ao final de 12 semanas não foi afetada pelos diferentes tratamentos, embora, aparentemente, o tratamento de alimentação controlada tenha apresentado piora na uniformidade do início para o final do período em questão, indicando a necessidade de reavaliação dos programas nutricionais indicados para a fase de crescimento de aves de postura.

De acordo com o manual de criação da linhagem, todos os tratamentos apresentaram uniformidade satisfatória, acima de $80 \%$ ao final do período de crescimento.

A composição corporal não foi afetada significativamente $(\mathrm{P}>0,05)$ pelos tratamentos (Tabela 6$)$, embora a carcaça das aves do tratamento de alimentação controlada tenha apresentado tendência a ser mais magra, com maior teor de proteína. Summers et al. (1987) também observaram que frangas às 16 semanas de idade apresentaram uma carcaça mais magra quando alimentadas com ração contendo menos proteína e energia.

Ao atingir a maturidade sexual, as aves necessitam, além de peso corporal adequado, de uma composição de carcaça ideal, levando em consideração tanto a massa magra, como a composição de gordura (Leeson \& Summers, 1989), pois ambos parecem ter efeito no peso do ovo (Leeson \& Summers, 1997). Os resultados de composição de carcaça obtidos neste experimento tiveram comportamento semelhante aos dados encontrados por Sakomura et al. (1993), que, ao avaliarem o uso de equações de predição para poedeiras leves às 52 semanas de idade, também não encontraram diferenças nos teores de gordura e proteína.
Apesar de alguns estudos indicarem que a ração fornecida às aves pode influenciar a composição corporal, maturidade sexual e produção de ovos (Summers et al., 1987), ainda não existem bons métodos para avaliar corretamente a composição corporal de frangas, por isso é dada mais ênfase ao peso corporal (Leeson \& Summers, 1997).

Os dados observados por Leeson \& Summers (1989) demonstram diferenças em relação à composição corporal encontrada no presente trabalho. Os autores observaram que as aves consumindo mais energia e proteína apresentaram carcaças mais magras às 20 semanas de idade. Tais diferenças podem ser atribuídas às mudanças genéticas ocorridas nos últimos anos. Além disso, no presente trabalho, não se utilizou variação no nível energético das raçãos, variando somente o consumo de ração para que atendesse às exigências das aves, de acordo com cada tratamentos, proporcionando adequada ingestão dos demais nutrientes.

\section{Fase de produção}

As aves mantidas em alimentação controlada durante a fase de crescimento apresentaram maior consumo de ração na fase de produção, quando alimentadas à vontade em relação àquelas que receberam alimentação à vontade na fase de crescimento (Tabela 7), provavelmente na tentativa de aumentar as reservas corporais para atingir o pico de postura em boa condição corporal. Talvez, o fato de receber alimentação restrita durante o crescimento também tenha influenciado nesta avidez por alimento. Por outro lado, o consumo de ração das aves alimentadas de acordo com a equação de EM durante o período de

Tabela 5 - Médias de uniformidade de peso inicial e final de cada fase, de 3 a 8, 9 a 12 e 13 a 18 semanas de idade

Table 5 - Means of initial and final weight uniformity of each phase, from 3 to 8, 9 to 12, 13 to 18 and 3 to18 weeks of age

\begin{tabular}{|c|c|c|c|c|c|c|}
\hline \multirow[t]{2}{*}{$\begin{array}{l}\text { Tratamento } \\
\text { Treatment }\end{array}$} & \multicolumn{2}{|c|}{$\begin{array}{c}3 \text { a } 8 \text { semanas } \\
3 \text { to } 8 \text { weeks }\end{array}$} & \multicolumn{2}{|c|}{$\begin{array}{c}9 \text { a } 12 \text { semanas } \\
9 \text { to } 12 \text { weeks }\end{array}$} & \multicolumn{2}{|c|}{$\begin{array}{c}13 \text { a } 18 \text { semanas } \\
13 \text { to } 18 \text { weeks }\end{array}$} \\
\hline & $\begin{array}{c}\text { Inicial, \% } \\
\text { Initial, \% }\end{array}$ & $\begin{array}{l}\text { Final,\% } \\
\text { Final,\% }\end{array}$ & $\begin{array}{c}\text { Inicial, \% } \\
\text { Initial, \% }\end{array}$ & $\begin{array}{c}\text { Final,\% } \\
\text { Final,\% }\end{array}$ & $\begin{array}{l}\text { Inicial, \% } \\
\text { Initial, \% }\end{array}$ & $\begin{array}{l}\text { Final,\% } \\
\text { Final,\% }\end{array}$ \\
\hline $\begin{array}{l}\text { À vontade } \\
\text { Ad libitum }\end{array}$ & 100,00 & $81,48 a$ & 94,43 & 94,44 & 97,23 & 91,1 \\
\hline $\begin{array}{l}\text { Controlado } \\
\text { Controled }\end{array}$ & 100,00 & $78,70 a$ & 100,00 & 85,55 & 100,00 & 95,8 \\
\hline $\begin{array}{l}\text { Equação EM } \\
\text { ME equation }\end{array}$ & 100,00 & $45,29 b$ & 95,53 & 95,55 & 100,00 & 92,8 \\
\hline CV(\%) & - & 14,27 & 5,09 & 9,37 & 2,50 & 8,55 \\
\hline
\end{tabular}

Médias, na mesma coluna, seguidas de diferentes letras diferem $(P<0,05)$ entre si pelo teste Tukey. Mean, in the same column, followed by different letters are different $(P<.05)$ by Tukey test. 
crescimento, não diferiu $(\mathrm{P}>0,05)$ em relação aos demais tratamentos. O consumo de ração neste período foi semelhante ao proposto pelo manual Lohmann (1995), considerando os níveis nutricionais da ração.

O consumo de ração ideal é reflexo da boa condição corporal em que as aves se encontravam ao final do período de crescimento. Além disso, a uniformidade ao início de produção foi de $100 \%$ para todos os tratamentos, o que facilitou o manejo nutricional, devido à semelhança nas exigências nutricionais de cada ave.

O maior problema de aves com uniformidade insatisfatória é a variabilidade na idade ao primeiro ovo e, portanto, no consumo de alimento, além do fato de o cálculo de porcentagem de produção não refletir o número real de aves que estão em postura (Leeson \& Summers, 1997).

As aves que receberam alimentação controlada apresentaram o menor peso corporal ao início da fase de postura em relação aos tratamentos à vontade e ao da equação de EM (Tabela 7). O peso corporal observado para os tratamentos foi superior ao recomendado (1350 g) pelo manual de criação da linhagem Lohmann (1995). Somente o tratamento de alimentação controlada apresentou peso corporal próximo ao recomendado.

O peso corporal das aves às 20 semanas de idade (início da fase de produção) foi uma resposta ao manejo nutricional adotado na fase de crescimento, sendo que o tratamento à vontade ingeriu a maior quantidade de energia e, por isso, apresentou peso corporal superior ao tratamento controlado. O tratamento da equação, por outro lado, ingeriu a mesma quantidade de energia do tratamento controlado e atingiu o mesmo peso do tratamento à vontade, provavelmente devido ao crescimento compensatório, que ocorreu após a primeira fase de crescimento, quando houve certa restrição de energia proporcionada pela equação.

Conforme apresentado na Tabela 7, ao final do experimento (35 semanas de idade), não houve diferença estatística $(\mathrm{P}>0,05)$ entre os tratamentos para peso corporal das aves, que foi semelhante ao recomendado pelo manual de criação da linhagem ( $\pm 1665 g$ ). Foi observada tendência de as aves do tratamento à vontade apresentarem menor peso e as aves do tratamento da equação, maior peso corporal nessa idade.

O peso corporal mais elevado pode ser fator positivo, desde que não alcance níveis muito altos, pois o peso corporal ao início de postura é muito importante para a produção de ovos, como relatado por Leeson \& Summers (1997), mas o limite entre peso corporal ideal e a obesidade da ave é pequeno. Segundo os autores, as aves que apresentarem maior peso corporal à maturidade sexual terão melhor desempenho e aquelas com peso corporal baixo, maturidade mais tardia e produção de ovos menores.

Os tratamentos testados no período de criação das aves não afetaram a porcentagem de postura (Tabela 7). Estes resultados indicam que as diferenças nos pesos das aves no início da produção, proporcionadas pelos tratamentos nas fases de cria e recria, não tiveram reflexos na produção de ovos, sendo que o desempenho das aves foi de acordo com o estabelecido para linhagem. Assim, verificou-se que os tratamentos da fase de crescimento foram eficientes em fornecer nutrientes para bom desempenho produtivo das aves.

Os resultados obtidos para massa de ovos (Tabela 7) revelaram que as diferenças de pesos corporais proporcionadas pelos tratamentos na fase de criação das aves não afetaram esse parâmetro. De acordo com Keshavars \& Jackson (1992), a menor ingestão de proteína afeta negativamente a produção de massa de ovos. Entretanto, no presente estudo, todas as exigências protéicas das aves foram atendidas, o que explica a boa produção de massa de ovos, sem diferenças entre os tratamentos.

Tabela 6 - Composição corporal das aves avaliada às 18 semanas de idade (médias de matéria seca [\%MS], proteína bruta na matéria seca $[\% \mathrm{~PB}]$ e extrato etéreo na matéria seca $[\%$ EE])

Table 6 - Carcass composition of pullets at 18 weeks (mean of dry mater [\%DM], crude protein on dry mater $[\% C P]$ and ether extract in dry mater [\%EE])

\begin{tabular}{lccc}
\hline Tratamento & \multicolumn{3}{c}{ Composição corporal (\%) } \\
Treatment & $\mathrm{MS}$ & $\mathrm{PB}$ & $\mathrm{EE}$ \\
& $\mathrm{DM}$ & $\mathrm{CP}$ & $\mathrm{EE}$ \\
\cline { 2 - 4 } & 43,77 & 49,74 & 41,96 \\
\hline À vontade & 42,50 & 51,62 & 39,51 \\
$\begin{array}{l}\text { Ad libitum } \\
\text { Controlado } \\
\begin{array}{l}\text { Controled } \\
\text { Equação EM }\end{array}\end{array}$ & 43,65 & 48,76 & 40,93 \\
$\begin{array}{l}\text { ME equation } \\
\text { CV }(\%)\end{array}$ & 2,96 & 3,94 & 5,92 \\
\hline
\end{tabular}

\section{R. Bras. Zootec., v.33, n.3, p.575-584, 2004}


Tabela 7 - Consumo de ração médio $(C R)$, peso corporal $(P C)$ às 20 e 35 semanas de idade, porcentagem de postura (PO) e conversão alimentar (CA) no período de 20 a 35 semanas de idade

Table 7 - Average feed intake (FI), body weight (BW) at 20 and 35 weeks, egg production (EP) and feed conversion (FC) from 20 to 35 weeks old period

\begin{tabular}{lccccc}
\hline $\begin{array}{l}\text { Tratamento } \\
\text { Treatment }\end{array}$ & $\begin{array}{c}\text { CR (g/dia) } \\
\text { FI (g/day) }\end{array}$ & $\begin{array}{c}\text { PC - 20 sem } \\
\text { BW at 20 weeks }\end{array}$ & $\begin{array}{c}\text { PC - 35 sem } \\
\text { BW at 35 weeks }\end{array}$ & $\begin{array}{c}\text { PO (\%) } \\
\text { EP (\%) }\end{array}$ & $\begin{array}{c}\text { CA (kg/duz ovos) } \\
\text { FC (kg/dozen eggs) }\end{array}$ \\
\hline $\begin{array}{l}\text { À vontade } \\
\text { Ad libitum }\end{array}$ & $104,45 \mathrm{~b}$ & $1447,1 \mathrm{a}$ & 1655,1 & 92,12 & 1,36 \\
$\begin{array}{l}\text { Controlado } \\
\begin{array}{l}\text { Controled } \\
\text { Equação EM }\end{array}\end{array}$ & $108,45 \mathrm{a}$ & $1397,1 \mathrm{~b}$ & 1691,1 & 93,13 & 1,40 \\
$\begin{array}{l}\text { ME equation } \\
\text { CV }(\%)\end{array}$ & $107,82 \mathrm{ab}$ & $1442,2 \mathrm{a}$ & 1710,7 & 92,75 & 1,40 \\
\hline
\end{tabular}

Médias, na mesma coluna, seguidas de diferentes letras diferem $(P<0,05)$ entre si pelo teste Tukey. Mean, in the same column, followed by different letters are different $(P<.05)$ by Tukey test.

Os resultados obtidos para conversão alimentar (kg de ração consumida por dúzia de ovos produzidos) indicam que os tratamentos aplicados durante a fase de crescimento não afetaram o desempenho das aves na fase de produção (Tabela 7). Em função do aumento do consumo alimentar das aves submetidas aos tratamentos controlado e da equação de EM, durante o crescimento, houve tendência em piorar a conversão alimentar, uma vez que as aves não aumentaram a produção de ovos.

O aumento do consumo de ração da aves submetidas aos tratamentos da equação de EM e controlado não acarretou incremento na produção, mas houve recuperação no peso corporal, promovendo pesos finais semelhantes (Tabela 7).

Apesar de algumas diferenças de peso corporal proporcionadas pelos tratamentos durante a criação das aves, pode ser constatado que estas diferenças não refletiram no desempenho das aves na fase de produção, tendo em vista os resultados de produção de massa de ovos obtidos durante esta fase (Tabela 7).

\section{Conclusões}

As equações testadas para predizer o consumo de EM de frangas de postura, nas fases de crescimento, não proporcionaram bons resultados. Por isso, são necessários alguns ajustes para que as equações reflitam as exigências reais das aves. Talvez o fator de correção de $20 \%$ sobre as exigências para mantença, proposto por Leeson \& Summers (1997), represente a alternativa mais adequada para a correção da deficiência energética causada pela equação.
Na fase de crescimento das aves, tanto a alimentação de acordo com as recomendações para a linhagem como a alimentação à vontade devem ser revistas, uma vez que ambas não proporcionaram o peso corporal esperado, sugerindo a necessidade de avaliação dos programas nutricionais e dos pesos recomendados às frangas Lohmann.

\section{Agradecimento}

À Fundação de Amparo à Pesquisa do Estado de São Paulo, pelo auxílio financeiro fornecido e à Granja Planalto S.A., pela doação das aves.

\section{Literatura Citada}

ASSOCIATION OFFICIAL ANALYTICAL CHEMISTS AOAC. Official methods of analysis. 16.ed. Washington, D.C.: 1997. v.1.

CHANDRAMOULI, T.; REDDY, V.R.; RAO, P.V. Response of laying hens to energy intake. Indian Journal Animal Science, v.58, n.3, p.372-6, 1988.

CHWALIBOG, A. A factorial estimation of energy requirement for egg production. Poultry Science, v.77, p.509-15, 1992.

KESHAVARZ, K.; JACKSON, M.E. Performance of growing pullets and laying hens fed low-protein, amino acid-supplemented diets. Poultry Science, v.71, n.5, p.905-18, 1992.

LEESON, S.; SUMMERS, J.D. Use of single-stage low protein diets for growing leghorn pullets. Poultry Science, v.61, p.1684-91, 1982.

LEESON, S.; SUMMERS, J.D. Response of leghorn pullets to protein and energy in the diet when reared in regular or hot cyclic environments. Poultry Science, v.68, p.546-57, 1989.

LEESON, S.; SUMMERS, J.D.Comercial poultry nutrition. 2.ed. Ontario: University Books, 1997. 350p.

MANUAL de criação e manejo Lohmann LSL, Uberlândia: Granja Planalto, 1995. 24p.

R. Bras. Zootec., v.33, n.3, p.575-584, 2004 
MANUAL de criação e manejo Lohmann LSL, Uberlândia: Granja Planalto, 2000. 27p.

MORETTI, C.S. Pontos críticos na recria e produção de poedeiras comerciais. In: CONFERÊNCIA APINCO DE CIÊNCIA E TECNOLOGIA AVÍCOLA, 1992, Santos. Anais... Santos: FACTA, 1992. p.129-36.

SAKOMURA, N.K.; ROSTAGNO, H.S.; FONSECA, J.B. et al. Alimentação de poedeiras leves, usando equações de predição das exigências energéticas. Revista da Sociedade Brasileira de Zootecnia, v.22, n.5, p.732-44, 1993.

SAKOMURA, N.K.; ROSTANGO, H.S.; EUCLIDES, R.F. et al. Alimentação de matrizes pesadas, usando equações de predição das exigências de energia matabolizável. Revista da Sociedade Brasileira de Zootecnia, v.24, n.4, p.570-89, 1995.

SAKOMURA, N.K. Exigências nutricionais das aves utilizando o método fatorial.In: SIMPÓSIO INTERNACIONAL SOBRE EXIGÊNCIAS NUTRICIONAIS DE AVES E SUÍNOS, 1996, Viçosa, MG. Anais... Viçosa, MG: Universidade Federal de Viçosa, 1996. p.319-44.
SCOTT, M.L.; NESHEIM, M.C.; YOUNG, R.J. Nutrition of the chicken. 3.ed. Ithaca: M.L. Scott \& Ass., 1982. 562p.

SILVA, R.; SAKOMURA, N.K.; BASAGLIA, R. et al. Exigências de energia metabolizável para frangas de postura de 1 a 18 semanas de idade. Revista Brasileira de Zootecnia, v.26, n.1, p.111-120, 1997.

SUMMERS, J.D.; LEESON, S.; SPRATT, D. Rearing early maturing pullets. Poultry Science, v.66, p.1750-57, 1987.

SUMMERS, J.D. Alimentação de poedeiras para máxima produtividade. In: SIMPÓSIO INTERNACIONAL DE NÃO RUMINANTES, 1992, Lavras. Anais... Lavras: Universidade Federal de Lavras, 1992. p.221-29.

Recebido em: 25/11/02

Aceito em: 06/06/03 